\title{
Un aspecto de la figura heroica en la literatura argentina contemporánea: Plop, de Rafael Pinedo ${ }^{1}$
}

Matías Lemo ${ }^{2}$

Resumen. Se analiza Plop (2002), del escritor argentino Rafael Pinedo. El protagonista de esta novela es un héroe en busca del autoconocimiento, quien ilustra, mediante la aventura, el mundo del que forma parte, construido a partir de las cavilaciones del autor en torno de todo aquello que podría empeorar dentro de su sociedad. De este modo, el relato, que recurre a la mitología y a la ciencia ficción, permite una lectura en torno a lo humano y a sus condicionamientos sociohistóricos: ¿es posible destruir la cultura? El marco teórico corresponde a la semiótica cultural de Iuri Lotman.

Palabras clave: Plop; Rafael Pinedo; Lotman; mitología; ciencia ficción; literatura argentina.

[en] One aspect of the heroic figure in contemporary Argentine literature: Plop, by Rafael Pinedo

\begin{abstract}
Plop (2002), by Argentine writer Rafael Pinedo, is analysed. The main character of this novel is a hero in search of self-knowledge, who illustrates, through adventure, the world of which he is a part, built from the author's thoughts about everything that could get worse within his society. In this way, the story, which draws on mythology and science fiction, allows a reading of the human being and his or her socio-historical conditioning: is it possible to destroy culture? The theoretical framework corresponds to the cultural semiotics of Iuri Lotman.
\end{abstract}

Keywords: Plop; Rafael Pinedo; Lotman; mythology; science fiction; Argentine literature.

Cómo citar: Lemo, M. (2019) Un aspecto de la figura heroica en la literatura argentina contemporánea: Plop, de Rafael Pinedo, en Anales de Literatura Hispanoamericana 48, 573-591.

\section{El hombre quiere vivir. La humanidad aspira a sobrevivir} Iuri Lotman (2007)

La sociedad mantiene una relación profunda con el mito heroico, entendido, desde la conciencia semiótica vigente, como descripción de las relaciones imaginables entre uno mismo y la otredad (Lotman y Mints, 1996). La razón de esto es que la mitología supone un relato de pregnancia simbólica profunda, fértil para interpretar

1 El presente trabajo es parte de una investigación que el autor realiza dentro de un grupo de estudios radicado en la USAL, titulado Identidad, género, cuerpo y camino del héroe en la literatura argentina (siglos XX y $X X I)$. Escrituras y reescrituras en diálogo con los antecedentes míticos de las tradiciones greco-latina $y$ cristiana. Lo dirige la académica Dra. María Laura Pérez Gras.

2 Universidad del Salvador, Buenos Aires. Argentina.

E-mail: matiaslemo@hotmail.com 
los rasgos y modos de comportamiento que constituyen el carácter de una comunidad.

En la Argentina de las últimas décadas, y en especial desde 1990, ciertas tendencias artísticas vienen buscando el socorro de un sustrato mitológico para pensarse y cuestionar la realidad social en la que se inscriben. En la literatura, en particular, esta tendencia suele adoptar recursos de la ciencia ficción especulativa ${ }^{3}$.

Ejemplo de esto es la obra del escritor Rafael Pinedo, quien nació en 1952 y estudió en la Facultad de Ciencias Exactas de la Universidad de Buenos Aires. Se graduó de computador científico y ejerció esa profesión. En paralelo, durante un tiempo, fue actor. En una entrevista (Alonso, 2004), contó que, a los dieciocho años, quemó todos los textos que había producido; y no volvió a escribir una sola hoja hasta los cuarenta. En 2002, recibió el Premio Casa de las Américas por Plop, que se publicó ese año en Cuba. Póstumamente, se dieron a conocer otras dos novelas suyas: Frío (2011) y Subte (2012), más el relato titulado «El laberinto» (2013).

Las cuatro obras comparten un tema, una estética y una ideología subyacente. Y también comparten un cronotopo típico de la ciencia ficción especulativa, donde los héroes, en tanto arquetipos atravesados por la historia, problematizan la cultura ${ }^{4}$.

En este artículo, la mitología será valorada por estar intrínsecamente ligada a la cultura (Lotman, 1996), es decir, porque implica datos para reflexionar sobre cómo el hombre se concibe a sí mismo y cómo se relaciona con el mundo. En esta dirección, la ciencia ficción distópica aporta el tono. El marco teórico adoptado, asimismo, deriva de la semiótica de Iuri Lotman, que permite leer, en la peripecia heroica del corpus, una modelización metafórica del funcionamiento del estado actual de la cultura.

\section{Lotman (1922-1993) ${ }^{5}$ sostuvo que la cultura no es un complemento facultativo}

${ }^{3}$ La definición de la variante de la ciencia ficción que se adopte depende del estudioso que de ella se ocupe. Pablo Capanna (2007, p. 189) prefiere el término «anticipación», según el cual, entiende: «La "anticipación" que hace la ciencia ficción va desde extrapolar tendencias actuales para el corto y el mediano plazo (con intención tanto "profética" como disuasiva) hasta proyectarse tan lejos como el fin del mundo. Cuando se traslada a un futuro lejano, ya totalmente desvinculado del presente, procura liberar la fantasía de cualquier prospectiva y llega a confundirse con la narrativa fantástica». Ángela Dellepiane (1989: 515-516), en cambio, prefiere el término «especulación». Ella llama especulativa a la ciencia ficción que «deja de lado la tecnología como fin en sí mismo, subordinando consecuentemente la imaginación científica a un interés focal en las emociones y actitudes humanas personales así como también en problemas sociales», por lo que, más que una narrativa científica, es una «narrativa de crítica social». Esta propuesta la sostienen Fernando Reati (2006) y Angélica Gorodischer (ap. Costa, 2000). Esta última, una de las cultoras destacadas del género, ha dicho: «No nos imagino escribiendo sobre imperios galácticos: los autores [argentinos] han hecho algo más cerca de lo metafísico que de lo épico». Para esta investigación, se asume la segunda definición.

${ }^{4}$ No es paradójica esta formulación: a pesar del concepto de «modelo original» del arquetipo, este no entra en contradicción con el sentido dialéctico de la historia, puesto que, como todo producto cultural, es resultado de fenómenos estudiables dentro de un contexto sociohistórico. Por eso la mitología admite actitudes críticas.

5 Por un lado, las influencias de Lotman, dice Pampa Arán, se pueden hallar en Bajtín, Lévi-Strauss, el estructuralismo praguense, que le llegó vía Jakobson, y aportes de la teoría de la comunicación y la cibernética (2001, p. 48). A su vez, se puede insertar a Lotman en su contexto histórico: los acontecimientos de los últimos años del siglo XX en la exUnión Soviética debieron de haber influido en su pensamiento. De crisis en crisis y de guerra en guerra, la movilidad del presente, el momento de transformación y de mutación, la necesidad de identificar las principales tendencias de un proceso de cambio cuyo futuro no podía predecirse, hizo que, en sus últimos ensayos, estuviera atento a lo que pudiera suceder en una escenario donde todo estaba por trastocarse (Pampa Arán 2001: 64). «La glásnost y la perestroika le permiten acceder al pensamiento de Occidente y tenemos constancia de que en sus últimos años estaba leyendo a Foucault, a Bourdieu y a 
para la humanidad, sino que es su requisito, sin el cual, la existencia del hombre es imposible. Se trata de un sistema de información ${ }^{6}$ no hereditaria, organizado y complejo, que recibe, traduce, compacta e interpreta la materialidad productiva de los sistemas sígnicos. Este artefacto semiótico procede de un comportamiento particular, en tiempos y espacios específicos, y está destinado a asumir una función puntual en la condición antropológica y evolutiva de la especie (Lotman 2000).

Este estudioso también elaboró el concepto de semiosfera (1996), que refiere al «lugar» donde se desarrolla la significación. De esta forma, todo el edificio semiótico puede ser considerado como un mecanismo único, que se recorta sobre el fondo de la no cultura. Justamente, «la semiosfera - expresó Lotman- es el espacio semiótico fuera del cual es imposible la existencia misma de la semiosis» (1996: 12).

Siguiendo el pensamiento de Lotman, las concreciones del aparato semiótico (las diferentes culturas y sus estados) son caracterizadas, en gran medida, por su vinculación con la mitología. Por un lado, las relaciones de sentido en torno a la figura heroica permiten interpretar modos sociales e históricos de sensibilidad ante lo heroico y, de allí, formas de traducción semiótica que favorecen la formación de series textuales o sagas ${ }^{7}$. Por otro lado, las conexiones que la mitología entabla con la literatura son paradigmáticas.

La correlación entre la literatura escrita y la mitología, el grado de proximidad de estas y su tendencia al acercamiento o alejamiento - dijo Lotman- constituyen una de las caracterizaciones fundamentales de todo tipo de cultura (1996: 129).

En lo que concierne estrictamente a la mitología, el aspecto simbólico ha sido subrayado por Mircea Eliade (2006), según quien, el término griego «mythos»se

Prigogine, recontextualizando sus tópicos, abriéndoles un espacio dialógico en sus propias búsquedas. En ellos encontró la constatación de que sus estudios no habían ido por caminos muy diferentes y además un punto de apoyo para sus nuevas conceptualizaciones» (Pampa Arán 2001: 64).

Por otro lado, Lotman, desde sus inicios, estuvo interesado en la manera en que las ideas filosóficas, las visiones del mundo y los valores sociales de una época dada se representan en la literatura. Por lo demás, aparte de las influencias señaladas por Pampa Arán, Zylko también menciona la psicología de Vygotski y la técnica cinematográfica de Eisenstein. Es decir, con esta variedad de fuentes, el Grupo de Moscú-Tartu al que perteneció Lotman nunca estuvo libre de cierto grado de eclecticismo (Zylko 2005: 1-2).

${ }^{6}$ Pampa Arán (2001: 49) hace una aclaración al respecto: «Debe tenerse en cuenta que cuando se habla de información, se lo hace desde el concepto de una teoría de la organización y control de los sistemas dinámicos, llamado cibernética (fundamento teórico de la automatización), en cuyo marco teórico están los conceptos, programas y lenguajes, tanto de máquinas como de sistemas orgánicos».

${ }^{7}$ Saga. La saga produce un ordenamiento particular de las posibilidades significativas condensadas en el mito y constituye un «enclave» en el escenario mítico general mediante el despliegue de líneas narrativas implícitas, sugeridas por la narración de este tipo; a la vez que una llave de lectura de series textuales no vinculadas inicialmente que se enlazan a partir de genealogías, personajes, geografías o acontecimientos comunes entre textos. La definición de saga contemporánea se vincula a aquella forma narrativa de epopeya oral en prosa, creada alrededor del siglo X por la aristocracia colonizadora de Islandia, según la tesis de Borges y Vázquez (1965):

«Las sagas son biografías de hombres de Islandia, a veces de poetas; en este caso se intercalan en el diálogo versos suyos. El estilo es breve, claro, casi oral, suele incluir, como adorno, aliteraciones. Abundan las genealogías, los litigios, las peleas. El orden es estrictamente cronológico; no hay análisis de los caracteres; los personajes se muestran en los actos y en las palabras. [...]. En las sagas, como en la realidad, hay hechos que al principio son oscuros y que luego se explican y hechos que parecen insignificantes y luego cobran importancia» (Borges y Vázquez 1965: 128). 
refiere a la palabra hablada, pero también a un cuento, historia o narración que es considerado/a como verídico/a, aunque no verificable, como se pretende que ocurra con el texto histórico denominado «logos». «El mito relata un acontecimiento que ha tenido lugar en el tiempo primordial — propuso Eliade_-, el tiempo fabuloso de los "comienzos" y en él, al tratarse de una historia sagrada, han intervenido seres sobrenaturales» (1974: 9). Asimismo, García Gual definió el «mito» como «... relato tradicional, memorable y ejemplar, paradigmático, de la actuación de personajes extraordinarios [...] en un tiempo prestigioso y lejano» (2008: 1). C. G. Jung (2002) vio en estas manifestaciones culturales una expresión de los arquetipos del inconsciente colectivo, mientras que Malinowski señaló el rasgo de realidad vivida de los mitos (1975). Y en la Argentina, Ernesto Sábato habló de una «ontofanía», como función implícita de este tipo de relatos (1982: 114).

Por todo lo anterior, resulta complejo encontrar una definición única para el término «mito». No obstante, como es sabido, a pesar de las contradicciones en las raíces mitológicas de los pueblos y civilizaciones de todo el planeta, existen puntos de conexión entre las manifestaciones de cada una, porque comparten núcleos estructurales muy parecidos entre sí. «¿Por qué la mitología es la misma en todas partes, por debajo de las diferencias de vestidura? ¿Qué nos enseña?», se preguntó Campbell (2010: 11-12). Y encontró una respuesta sobre la base de un entendimiento de la naturaleza mitológica como fuente de la vida.

En la literatura argentina, la relación con la mitología se remonta a las Crónicas de Indias, cuya reverberación proteica llegó, por transmisión popular, hasta el siglo XIX, como ha sucedido con el tópico fundacional del «hambre» y la antropofagia fratricida, que, ya por vía escrita, alcanzó las letras de la actualidad. Por consiguiente, la función narrativa heroica se halla presente desde los orígenes. Otro ejemplo de lo mismo es la mitologización del personaje típicamente decimonónico de «la cautiva» (que no constituye un ciclo, a la manera del troyano, por caso; pero sí es, sin duda, una saga muy fértil ideológica y narrativamente). Y un ejemplo más es la figura mítica de los próceres («héroes») argentinos, vinculados con la identidad nacional en el relato canónico ${ }^{8}$, o incluso la adopción del mito romántico del «genio» o del mito ilustrado del «buen salvaje». En el siglo XXI, se puede señalar, entre tantos textos literarios particulares con referencias mitológicas, la antología coordinada por Guido Indij para la editorial Interzona, Historias del fin del mundo (2013), o la novela reciente El amo bueno (2016), de Damián Tabarovsky.

Ahondando en la cuestión, otro de los tópicos centrales de la literatura argentina relacionado con la mitología es el del traidor y del héroe, popularizado, sobre todo, por Borges. En tiempos más recientes, ese binomio se ha releído con vistas a narrar el terrorismo de Estado de la última dictadura cívico-militar (López Casanova 2008; Drucaroff 2010). Y han aparecido nuevos personajes ambiguos a la manera borgeana («Tema del traidor y del héroe», «La trama», «El General Quiroga va en coche a la muerte»); así la montonera irresistible que enamora a sus torturadores o se enamora de ellos (Noche de lobos, de Abel Posse). En esta dirección, son significativas otras dos encarnaciones del héroe: el desaparecido político, como mártir (Ni muerto has perdido tu nombre, de Luís Guzmán); y el sobreviviente,

\footnotetext{
${ }^{8}$ Cfr. Lojo 2010 y Kohan 1999.
} 
como héroe caído (Las islas, de Carlos Gamerro). Asimismo, se podría rastrear, dentro de textos argentinos escritos en español, el uso de mitologías regionales, como la wichí (Eisejuaz, de Sara Gallardo) o la mapuche (Una excursión a los mapunkies, de Agustina Paz Frontera). Como se va perfilando, la relevancia del héroe en la literatura argentina reside en el hecho de ser un sintetizador entre lo mitológico y lo histórico.

El héroe, se dirá para continuar, ilustra el funcionamiento de la cultura (Lotman 2000): es dinámico, es decir, puede valorarse de modo positivo en determinado período, y tal cualidad, en otro intervalo temporal, puede ser negativa. Esto ha sucedido en la Argentina con figuras históricas que han cambiado de signo, revisitadas a la luz del discurso historiográfico contemporáneo o en la nueva novela histórica (Él, Juan Facundo, de Abelardo Arias; Santa Evita, de Tomás Eloy Martínez; La princesa federal, de María Rosa Lojo; Argentina con pecado concebida, de Federico Andahazi).

Ese dinamismo de la cultura, que conecta memoria y olvido, para asegurar su permanencia (Lotman 2000; Ricoeur 2013), permite que los mitos que explican cuestiones ligadas a la comunidad, a la nación, al universo cambien para adaptarse según varíen las condiciones históricas, sin perder, no obstante, su identidad.

Este fenómeno propio de la dialéctica cultural facilitó que la ciencia ficción naciera emparentada con la mitología. Y quizá se pueda proponer la supervivencia de esta en aquella, luego de que se postulara la muerte de Dios y cayeran en descrédito los relatos mitologizantes-mesiánicos del siglo XX: el socialismo, el marxismo, el nazismo, el fascismo, el cientificismo y el capitalismo (Reati 2006; Capanna 2007). Es decir, una vez que se comenzó a desconfiar de lo sobrenatural de forma generalizada, la mitología per se dejó de dar respuestas para la vida, abriéndole paso a la ciencia ficción.

Sin embargo, ella tampoco brindó un norte: precisamente, cuando se afianzó este tipo de relato en los Estados Unidos - donde mayor desarrollo ha tenido el género- es, más o menos, el momento que se ha señalado como «inicio» de la posmodernidad (con lo que el lugar común de la teoría al respecto indica de «desorientación»). Además, la ciencia ficción —en el sentido de relato «anticipatorio»- se agotó pronto. El lector dejó de sorprenderse ante las historias de bombas atómicas, viajes a la luna, inteligencias artificiales o robots, como, a su tiempo, se había desinteresado por lo sobrenatural mitológico?

En estos días, el género estudiado se ha vuelto un tejido muy laxo que se impone a la creación de diversos artistas, sin que sea posible, no obstante, afirmar que se trate de «ciencia ficción». Muchísimos escritores argentinos han comenzado a trabajar sus historias bajo esta malla, como es el caso de César Aira (Los misterios de Rosario), Sergio Chejfec (El aire), Oliverio Coelho (Borneo), Marcelo Cohen (Donde yo no estaba), Angélica Gorodischer (Las repúblicas), Daniel Guebel (Los elementales), Pedro Mairal (El año del desierto), Guillermo Saccomanno (El oficinista), entre otros varios ${ }^{10}$, algunos de ellos analizados por Fernando Reati (2006) y Elsa Drucaroff (2010). A su vez, gran parte de la novela

\footnotetext{
${ }^{9}$ Esta situación también favoreció el surgimiento del género, hoy en boga, de la fantasía heroica o fantasy.

${ }^{10}$ Aquí se menciona el tipo de texto narrativo por excelencia, la novela. Sin embargo, esta corriente afecta otros géneros, como la historieta (El cuervo que sabía, de Kwaichang Kráneo, publicada durante el bienio 20082009) e incluso la poesía («La toma de Constantinopla», de Horacio Castillo, publicada en el 2003).
} 
policial reciente podría ubicarse, en menor o mayor medida, bajo esta misma red ${ }^{11}$.

Lo común en todos estos casos, y en la obra de Rafael Pinedo, es lo que se llamará un poshumanismo, de acuerdo con Osvaldo Di Paolo, que revela la descentralización del individuo y manifiesta el caos, el miedo y el enfrentamiento de fuerzas opuestas que, entre la soledad y el peligro, conducen a la hipotética destrucción del género humano, en oposición a las promesas evolucionistas.

Osvaldo Di Paolo, cuando habla de «poshumanismo», se refiere, concretamente, a:

...la pérdida de la capacidad del individuo de utilizar la razón para solucionar problemas sociales y culturales, llevándolo a depender de dinamismos inadecuados que lo excluyen de una posición privilegiada» (2012: 41-42).

Y en el libro Gemidos y explosiones apocalípticas... (2013), el poshumanismo involucra un sentido catastrófico escenificado en un espacio citadino en ruinas, donde la desesperanza de un futuro mejor carcome al individuo. La consecuencia de esto en la literatura, se agrega aquí, es que el hombre no se diferencia de los animales, las máquinas u otras formas eventuales de lo «inhumano».

Dicho de otra manera, en la literatura argentina contemporánea, aparecen panoramas distópicos, con una concreción en particular, el apocalíptico, y, en especial, el posapocalíptico (el cronotopo que recorre la obra de Pinedo). El mito, entendido de forma tradicional, en su remisión al pasado, y la utopía, en su remisión al futuro, ya no explican la situación del hombre (como tampoco tiene éxito la remisión al presente, propia de la ideología y de la política). En consecuencia, la mitología adopta los recursos que le proporciona la ciencia ficción, para abrir un camino expresivo nuevo donde el hombre es considerado en su amplitud tanto sincrónica como diacrónica.

Entonces, aquí, se sostiene que el héroe busca el autoconocimiento (Campbell 2010) y así, en su derrotero de aventuras, reconoce el lenguaje de su entorno. El protagonista de Plop, la novela de Rafael Pinedo que se analizará a continuación, tiene estas cualidades.

En Plop, el primero de los textos de la saga de Rafael Pinedo, la narración parte de las consecuencias de una catástrofe, de la que no se explican las causas. Solo queda claro que el mundo se transformó drásticamente. Este hecho sacude la cultura y la pone en contacto con bordes de realidad que antes no existían (o parecían no existir). La sociedad, dicho con otras palabras, es arrojada hacia el límite de sí misma. Y ahí, en la frontera, surgen modos extraños de relacionarse con el tiempo, el espacio, los objetos, los animales y los otros hombres.

Ahora bien, este cambio profundo no es total, ya que, como propuso Lotman, la cultura es un requisito para la existencia del hombre; aunque Pinedo afirmó que su novela «tiene que ver con la destrucción de la cultura» (Friera 2006). La contradicción se resuelve de este modo: el novelista imaginó una variación sobre su propio espacio-tiempo, que no logra ser radical. ¿En qué consiste tal variación?

\footnotetext{
${ }^{11}$ Cfr. Gemidos y explosiones apocalípticas poshumanas, de Osvaldo Di Paolo, donde este investigador realiza un estudio comparativo entre la novela negra y la ciencia ficción hispanas.
} 
En primer lugar, los personajes de Plop perdieron un impulso básico — que se denominará «curiosidad», por no disponer de otra palabra, sin intenciones de incurrir en psicologismos-, aquel movimiento que, surja de donde surgiera, hace que el hombre vaya necesariamente hacia las cosas y se pregunte sobre sí mismo en el encuentro con lo otro. Estos individuos abúlicos, en cambio, no cuestionan lo que sucede, porque es un trabajo inútil para su forma de supervivencia. Andan sin respuestas - lo cual no sería inusual-, pero, fundamentalmente, no tienen respuestas, porque viven sin preguntas —y esto sí ya sería más extraño-

En segundo lugar, la modelización que sobre ellos ejerce la cultura se redujo a contraposiciones primordiales; una de ellas, vida/muerte, aquí subsidiaria exclusiva del par alimentación/inanición. Otro ejemplo ilustrativo de la transformación cultural es la oposición cerca/lejos, que determina, para estos personajes, lo seguro y lo inseguro, sin puntos intermedios.

En tercer lugar y de algún modo, la semioesfera perdió coherencia. Hubo una reducción de los elementos dinámicos y de los estáticos inclusive (que constituyen, en interdependencia, la cultura), hasta llegar al mínimo indispensable para existir. Como correlato de esto, creció la franja de la no-cultura. Por ejemplo, lo desconocido amenaza el espacio de lo conocido. Pero, semióticamente, parece improbable que algo del orden de lo que no tiene nombre se vuelva un peligro. No obstante, esto acontece, en la medida en que no se dispone de los mecanismos para interpretar lo ajeno como conocido, o bien, lo desconocido como conocible. Así nacen algunas formas del miedo: un estímulo oprime, pero no se sabe qué es. Del mismo modo, nace la violencia: existe un estímulo que produce miedo, pero no se puede saber qué es; en consecuencia, se lo debe mantener a distancia o eliminarlo. $\mathrm{Y}$, al actuar de esta forma, se descarta un texto potencial de ser incorporado en la memoria colectiva que, de esta forma, no se empobrecería cuantitativamente, aunque tampoco se enriquecería.

En el grupo de Plop, sin embargo, la memoria sí se empobreció porque se perdieron nombres, valores, costumbres, textos. Los personajes coexisten con vestigios del pasado, pero sin identificarlos, porque no entablan una relación dialéctica con ellos: las personas ocupan el mismo lugar que los objetos residuales de otras épocas, de forma paralela en lo espacial, pero divergente en lo temporal.

De esta manera, se identifica la idea de «progreso», implícita, como es recurrente en la ciencia ficción. Los personajes se encuentran con electrodomésticos que, sin electricidad, no sirven en absoluto. Por lo demás, tampoco se mantiene información sobre cómo se usaban en otro tiempo (este elemento escenográfico, los artefactos de otra época que ya no tienen uso, es típico de la ciencia ficción prospectiva o distópica). ¿Adónde condujo el «progreso»? Aquí desaparece la impresión, infundida por la tecnología, la ciencia y la economía, de sentir que se tiene control sobre la vida.

Cabe agregar que la sociedad del siglo XXI que se halla en el imaginario del escritor, con su estructura capitalista, en Plop se convirtió en una comunidad de cazadores-recolectores nómadas. La forma de intercambio comercial única es el trueque: la comida se vende por cuchillos o niños vírgenes. La vestimenta está despojada de toda noción esteticista; se construye con pedazos de nailon y cuero, y es funcional a las nuevas actividades, a la lluvia constante y a los eventuales ataques de otros grupos. Los objetos son valiosos o no de acuerdo con su utilidad. 
Las armas se defienden con la vida, y en especial, el metal no oxidado.

Además, en la transformación posible que imaginó Pinedo, el proceso de cambio más frecuente es el de la simplificación. Esto sucede con las «necesidades primarias», como la alimentación y el sexo, desprovistas de los signos con que la cultura del autor las complejiza y las convierte en necesidades también simbólicas. Por consiguiente, la manera despojada y causal de relacionarse con el cuerpo propio se repite en la interacción con los otros. El verbo que los personajes emplean para referirse al sexo, por ejemplo, es «usar», y en ningún caso la cópula implica una vinculación afectiva o moral.

La paternidad, entendida de manera simbólica, no existe: no hay «padres» en la novela, solo «hembras» que tienen «crías». Y los hijos, por su parte, son indeseables, ya que representan un estorbo en su período de lactancia y una desventaja para la mujer al momento de luchar. De todos modos, estos hombres no entienden la procreación, y los embarazos son infrecuentes, por la anemia.

Asimismo, la separación social entre lo femenino y lo masculino se atenuó. El rasgo básico de distinción es la aptitud física para el combate y la obtención de comida, para lo cual no importa la sexualidad. Solo la fortaleza corporal marca la diferencia, puesto que determina quién ha de supervivir y quién ha de ser «reciclado» (convertirse en alimento para los chanchos). De ahí que también sean frecuentes las prácticas homosexuales, como referencia a una indistinción primordial.

A su vez, un elemento estático fundamental de la cultura que desapareció es la lectoescritura y lo que se conoce como cultura del texto. En esta dirección, un personaje para mencionar es «la vieja Goro», que parece ser la más anciana del asentamiento (2012: 21), donde se la venera casi con misticismo por su sabiduría y poder. Vive en silencio, retraída, y siempre es «áspera» (2012: 21); y cuenta con privilegios y libertades que el resto no tiene. Cuando ella está agonizando, le entrega a Plop un sobre de cuero que lleva escondido entre las arrugas infinitas de su pecho, un libro.

Aparte de la vieja Goro, existe un reducido grupo de «iniciados», que se junta cada cierto tiempo, de noche y a escondidas, a leer. Plop, en determinado momento, es incluido entre ellos. Él debe comenzar el aprendizaje de cero, es decir, desde el silabeo. Y a propósito de la lectura, los libros prácticamente desaparecieron y nadie sabe escribir.

En lo que se refiere a Goro, resulta pertinente esta historia. Diez noches después del solsticio de verano (lo que vendría a coincidir con el Año Nuevo cristiano), todos celebran una fiesta:

Era para el fin del calendario. Se tomaba alcohol y se hacía comida colectiva. Era la única vez que todos comían lo mismo. [...]. También se masticaban unos hongos que hacían soñar despierto. Los más viejos o importantes podían hacerlo desde el inicio. Los demás tenían que hacerlo al final, antes de la ceremonia del Todo Vale, cuando cada uno hacía lo que quería, cómo y con quien quería (2012: 39).

En una de estas festividades, la vieja Goro se paró de golpe y, con una voz extrañamente clara, dijo: «Voy a leer». «Va a leer. Va a leer», se corrió la voz. 
Todos se pusieron serios. Las autoridades se acercaron corriendo. Plop no entendía qué pasaba. «Voy a leer», repitió Goro. «La vieja se metió la mano entre las tetas y sacó un sobre de cuero que llevaba colgado del cuello. De ahí extrajo unas hojas de papel. Plop nunca había visto tantas juntas y enteras». Todos los ojos estaban fijos en ella, cuando comenzó a leer: "Hace diez o quince millones de años...», y describió la formación del mundo de acuerdo con la teoría del Big Bang (insertada en el texto como cita, en cursiva). Plop se aburría, pero la gente a su alrededor estaba de rodillas y en trance:

Fue una explosión que abarcó todo el Universo que podemos ver, fue hace diez o quince millones de años, tan lejos en el tiempo como podemos rastrear en la historia de nuestro Universo, y continuará por los millones de años que vienen, y quizás para siempre.

Para siempre.

Para siempre (2002: 42).

Entonces gritó «¡Todo Vale!», y los oyentes se lanzaron a «usar» al que tenían al lado, sin siquiera fijarse quién era. Goro sonrió y dijo: «Bestias!» (2012: 43).

En este fragmento (2012: 39-43), se observa cómo el personaje que sabe leer capta la atención de todos, que no solo no saben leer, sino que no pueden entender el sentido de las palabras que oyen, porque, en su gramática, no tienen términos como «Universo», «años», «millones», «historia». Y, paradójicamente, el texto leído es sobre el origen del mundo, sobre el cual asegura la continuidad de su existencia, coherente ante un estado posapocalíptico, aunque esto no implique sí o sí la continuidad de la especie humana. Además, ella, que sabe leer, no se suma al Todo Vale; se limita a señalar la bestialidad de los otros.

Dejando esta cuestión de lado, también desaparecen las formas de cortesía. Sin embargo, unos signos, como el saludo, se complejizan. Por ejemplo:

...intercambiaron los saludos: las manos en el pecho del otro, los labios, cerrados, en los labios del otro, y la fórmula:

-Acá se sobrevive.

—Acá se sobrevive (Pinedo 2012: 13).

Por último, otras nociones que se modifican involucran el libre albedrío (estos individuos no tienen discernimiento para evaluar qué hacer y qué no de forma racional), el derecho (que se reduce a una sola ley, la del más fuerte) y la propiedad privada (que se pierde como bien capital).

Por el contrario, reaparecen signos de épocas pasadas, como la organización tribal, la (relativa) memoria colectiva expresada a través de la oralidad, la percepción mítica y cíclica del tiempo, el cuerpo como medida de todas las cosas, el determinismo (casi igual que en los reinos animal y vegetal).

En cambio, el paisaje es nuevo (casi) por completo: a diferencia de las ciudades actuales, este es un territorio que no varía, compuesto por superposición de desperdicios:

El suelo siempre es plano. Debajo de la basura siempre es plano. 
La Llanura, la llaman. El horizonte está apenas cortado por grandes pilas de escombros y basura (Pinedo 2012: 20).

Además, llueve de manera permanente. El agua suspendida en el aire es como «una pared líquida que golpea la cabeza» (2012: 18), y borra las huellas que el hombre imprime en la naturaleza y genera barro, como metáfora de putrefacción. Los animales mutaron, como la vegetación, y se volvieron enemigos peligrosos.

Hasta aquí se consignó lo que ha desaparecido o cambiado en la propuesta ficcional de Pinedo con respecto a su mundo. También sería propicio, ahora, identificar qué es lo que permanece después de la debacle, lo que equivaldría a un estudio sobre qué es lo más humano de lo humano (si fuera completamente lícito plantear una gradualidad ontológica del concepto). Con tal motivo, se procede a dilucidar una cuestión pendiente, que es la relación entre Plop y la mitología, en general, y el camino del héroe, en particular.

Lotman señaló que el mundo mitológico se compone de objetos concebidos en un mismo rango (2000: 145). Esto ya se dijo aquí, en cierto modo, cuando se anotó que los personajes de Plop carecen de curiosidad y son reaccionarios, porque para ellos «todo es igual» ${ }^{12}$. Las cosas del mundo, para ellos, se describen mediante $e l$ mismo mundo, construido de la misma manera.

Estos sujetos no desarrollaron una función lingüística metatextual. Para cualquiera de ellos, por caso, tener relaciones sexuales con una persona durante un Todo Vale es exactamente igual a hacerlo con cualquier otra, y de hecho, es equivalente a la suma de las experiencias sexuales previas, sin matices. «Comprender» que ha tenido sexo implica reconocer el sexo, o bien se podría decir hacer el Sexo, con mayúscula.

A su vez, Lotman caracterizó estos mundos por la indivisibilidad de los rasgos (2000: 145). Esto significa que la cultura o el sistema semiótico fundante no permite realizar traducciones. Cuando el grupo de Plop, por ejemplo, se cruza con otro colectivo de hombres, no puede percibirlo como un conjunto de pares; los otros son, en el mejor de los casos, una potencial fuente de alimento, por medio del trueque; en el peor y más habitual de los casos, enemigos, al igual que un grupo de gatos salvajes $u$ hongos venenosos. Sus ritos y costumbres no son vistos como un sucedáneo de los propios: encarnan partes de Universo incognoscibles, lo otro absoluto, la no cultura o, incluso, la anticultura.

En estas mentalidades, agregó Lotman (2000: 145), las cosas suceden una sola vez. Las festividades del Todo Vale son, en cada caso, la misma, ya que la suposición de que un fenómeno se repita implica su inclusión en un conjunto general (las fiestas, y dentro de estas, el Todo Vale, junto con los bautismos y el Karibom, otra celebración del asentamiento de Plop), esto es, la existencia de un nivel de metadescripción.

Sin embargo, el mundo que proyectó Pinedo, que es de un solo rasgo en el sentido de jerarquía lógica, es jerárquico en grado sumo en el plano axiosemántico. De este modo, se comprenden los tabúes del grupo de Plop, entre ellos, la prohibición de mostrar los dientes; o las etapas del Todo Vale, que jamás son

\footnotetext{
${ }^{12}$ Esta proposición, «todo da lo mismo», «todo es igual», tiene que ver con la enfermedad vital de Barroso, el protagonista de la novela de Sergio Chejfec El aire (1992). Además de esta coincidencia, en el texto de Chejfec, también se construye un cronotopo distópico poshumano.
} 
intercambiables o dispensables, como así también las diferencias sociales plenamente delimitadas.

Estas consideraciones conllevan la idea del mito como un fenómeno de la conciencia. En un mundo así dibujado, tiene lugar un tipo de semiosis bastante específico, que se reduce, en general, a la nominación: el signo, para la conciencia mitológica, es análogo al nombre propio. Y como este se define por la tautología, equivale a la cosa designada: Goro es Goro y Plop es Plop. Esto da lugar al uso mágico del lenguaje, como sucede con el saludo típico ya citado: «-Aquí se sobrevive. / -Aquí se sobrevive».

De lo expuesto, se desprende una manera singular de concebir el tiempo y el espacio. Por un lado, este último no aparece como un continuum de signos, sino como un conjunto de objetos portadores de nombres propios. Recuérdese aquí que la semiosfera, entendida como el ámbito de influencia donde se desarrolla la cultura, está recortada sobre el fondo de la no cultura. En el caso del grupo de Plop, está, de un lado, el asentamiento propio, el centro del Universo; del otro lado, está todo lo demás, que vendría a ser un infinito de no cultura, interrumpido por islas de emanaciones culturales: por ejemplo, aquel grupo asociado al intercambio de alimento, que, en realidad, vendría a ser el Alimento (no la traducción «el grupo de humanos como nosotros, con distintos hábitos, que nos truecan comida por $\mathrm{x}$ valor»). Esto significa que el espacio, para el pensamiento mitologizante, es siempre pequeño y cerrado, es decir, tiene un carácter finito y contable. Los más viejos del grupo de Plop, por ejemplo, han escuchado decir que, de la otra parte de donde sale el sol, a una distancia inimaginable, hay una gran cantidad de agua, que algunos llaman «mar»; pero es un relato en el que nadie cree, porque no pueden concebir esa distancia.

Por el otro lado, la conciencia mitológica está subordinada a un tiempo cíclico. Esto, en cierto modo, resulta incomprensible de acuerdo con la conciencia actual, que tiende a pensar en la circularidad como la mera oposición a la linealidad propia del sistema semiótico vigente aquí y ahora. Sin embargo, existe, para el primer tipo de conciencia, un isomorfismo entre el nacimiento y la muerte. En Plop, en efecto, no hay distinción entre nacer y morir, y no por la noción de Eternidad, que implicaría un renacer, sino porque da exactamente lo mismo vivir que morir.

Aquí téngase presente que Lotman ha dicho que la relación entre la literatura y la mitología es paradigmática de la tipología de cada cultura. Lo propio de la primera es la linealidad mínima e indispensable del relato; mientras que, como se dijo, lo cíclico lo es de la segunda.

En el ensayo titulado «Literatura y mitología», Lotman escribió que «el mito no se contaba, sino que se ejecutaba en la forma de una compleja representación dramática en la que la narración verbal no era más que un componente particular» (1996: 132). En consecuencia, la literatura y la mitología son antinómicas. Incluso Lotman afirmó esto: «La literatura solo tiene trato con formas destruidas, vestigiales, del mito y contribuye ella misma a su destrucción», precisamente, por el modo de ser divergente de cada una.

En lo que se refiere a la estructura textual de Plop, el autor no solo trabajó la mitología desde el mundo de sus personajes (cronotopo), sino también desde la misma forma del relato. La novela se compone de un prólogo, de capítulos intermedios y de un epílogo. En el prólogo, el narrador refiere cómo alguien, desde 
un pozo, espera la muerte próxima por lapidación, es decir, el relato comienza por la muerte de su héroe. Los episodios siguientes tienen forma de flashbacks, que, retóricamente, se corresponden con una palada de tierra que cae sobre el protagonista. Cada flash constituye una postal, que remite a un momento de la existencia de este individuo; y cada flash, de acuerdo con la conciencia mitológica, no sería un «etapa en la vida de», sino el Ser monolítico, el Héroe.

En el primer capítulo, «El nacimiento», se cuenta sobre una parturienta que camina atada a un carro durante una procesión; llueve y el agua limpia la sangre que le baja por las piernas; el bebé cae y, al golpear contra el barro, hace «plop». Ese ruido dará nombre al héroe de esta historia. El epílogo concluye con las siguientes líneas:

Nunca existió otra cosa que barro.

Solo figuras cubiertas de barro, como él.

Lo bajan con una soga atada a un pie. Por la mitad lo sueltan.

Cae al barro.

Hace plop (2012: 131).

La estructura, como se evidencia, es «circular» (entiéndase «cíclica»), y la aventura podría ser leída a partir de cualquier capítulo. Evidentemente, esto se conecta con la idea de que todo episodio supone la actualización de la cadena, de acuerdo con la mentalidad mitologizante:

La narración de tipo mitológico — dijo Lotman — no se construye según el principio de la cadena, como es típico del texto literario, sino que se enrolla, como un repollo, en el que cada hoja repite con ciertas variaciones todas las demás (1996: 11).

En adición, aportan sentido los movimientos discursivos del narrador héteroextradiegético. Este despoja su relato de comentarios accesorios. Los fragmentos descriptivos son muy breves y escasos. Con respecto a los personajes, no son pintados de manera externa, ellos cobran entidad a través de la acción («narración sumaria»), sin contar tampoco con descripciones interiorizantes. El registro léxico y las oraciones también son sencillos («frases cortas y secas», dice el mismo narrador; 2012: 26). La extensión promedio de los párrafos es de tres líneas, y la sensación general es la de leer una lista. De forma permanente, asimismo, el narrador emplea repeticiones verbales que remiten al mundo residual del cual provienen estos sujetos y prescinde de adjetivos (reduciendo los juicios de valor evidentes). En suma, estos recursos constituyen una prosa aséptica y distante, que surge de una decisión estética.

Además del valor puramente plástico, esos recursos resultan un aporte funcional, en un doble sentido: sin la distancia entre el narrador y lo narrado, por un lado, el lector no toleraría la crudeza de un estado de cosas cuya narración resultaría inevitablemente sádica (violaciones y demás parafilias, asesinatos, abusos, crueldad, la muerte latente en todos los objetos, etc.); y, por el otro lado, dichos recursos, en su sencillez, remiten a la «destrucción de la cultura», es decir, a una hipotética disminución de la memoria colectiva. 
Por último y sobre todo, la retórica descripta se conecta con la esencia elemental propia del mito. Entonces, en este punto, se puede afirmar que, entre otros, uno de los textos que supervive es, en el estado de cultura de Plop, la mitología. Y, en especial, sobrevive el monomito del héroe, con el cual es compatible la forma de la novela.

Por su parte, Campbell afirmó que los héroes de numerosos mitos de tiempos y regiones dispares comparten esquemas y desarrollos, que se estudian en El héroe de las mil caras. La idea rectora de este estudio es que el héroe se lanza a la aventura desde su mundo cotidiano a regiones de maravillas sobrenaturales; luego tropieza con fuerzas fabulosas y acaba obteniendo una victoria decisiva; para después regresar de esta aventura misteriosa con el poder de otorgar favores a sus semejantes. Y agregó Campbell: «Ya sea el héroe ridículo o sublime, griego o bárbaro, gentil o judío [sic], su aventura varía poco en cuanto al plan esencial» (2010: 29).

¿Qué sectores de Plop ilumina esta información? El protagonista es un héroe y la novela cuenta su periplo vital. El motor del texto es la superación consecutiva de pruebas que atraviesa él. Y a diferencia de los antihéroes, como podrían ser los personajes de la literatura existencialista (El hombre sin atributos, por caso), Plop tiene un «llamado» y lo asume. Este llamado es la búsqueda de libertad, en un sentido individual e individualista: en su asentamiento, solo tienen derecho a elegir qué hacer los líderes; todos los demás dependen del grupo, con sus costumbres, hábitos y tabúes. Plop decidirá convertirse en líder, y esto conducirá su caída.

Esta figura está marcada desde el nacimiento, ya comentado. Su madre, cuando lo pare durante una migración, continúa caminando (si se detenía, moría). Al niño lo recoge la vieja Goro, no por compasión, sino por especulación: si sobrevive, puede ser su esclavo; si muere, puede servir para alimentar a los chanchos. Entonces lo mete en su morral. Cuando llegan al nuevo sitio (recuérdese que se trata de una comunidad nómada), la anciana coloca al bebé en el pecho de la madre («la Cantora», que no vuelve a cantar después de parir). «Cuenta la vieja que se prendió a la teta de la madre con las manos, como un mono. Que así, por la vieja y por sus manos, se salvó» (2012: 15). En esta cita, no se debe pasar por alto, por un lado, la comparación animalizadora; y, por el otro, la relevancia de Goro y el hecho de que Plop, como es típico del héroe, es un individuo que tiene un nacimiento especial. Será un hombre distinguido por el fatum y el poder de hacerse con «sus propias manos», con lo cual se genera, en una sociedad reticente al cambio, un inevitable sino trágico.

Por lo demás, Goro representa la figura guía o, aquí en un sentido literal, la madrina. "Cuando llega el solsticio de invierno, se hace la Asamblea de los Nombres». Allí Goro definirá la identidad de Plop:

A todos los que tienen más o menos diez solsticios, cinco de verano y cinco de invierno, se les pone nombre y se los destina definitivamente a una Brigada, en la que permanecen para siempre. Alguno, caso raro, consigue cambiar (2012: 22).

Cuando llegó el turno de Plop, la vieja Goro dijo «Plop»: 
—Cómo? - dijo el Comisario.

-Plop - repitió.

— ¿Por qué? - preguntó ante el asombro general.

-Es el ruido que hizo al caer en el barro, cuando nació - y volvió a mirar al suelo (2012: 22).

Hubo una carcajada popular, que a Plop le retumbó en la cabeza. Y agrega el narrador:

Se paró de un salto, miró para abajo y dijo en voz muy alta:

-Me llamo Plop. Y pertenezco a Servicio Dos (2012: 22).

Y que no confunda el hecho de que mire al suelo, no es un indicio de humildad: cuando reafirma su identidad en voz alta, no levanta la vista para no mostrar los dientes, uno de los tantos tabúes del grupo. El gesto está señalado por la presunción; él será uno de los que consiga cambiar y alterará el orden cósmico (el grupo es el ombligo del mundo, y una puesta en abismo, en su estructura, de la organización del Universo). En este episodio reside el inicio del camino heroico de Plop.

En esta orientación, son relevantes algunos títulos de capítulos: «El nacimiento», «El nombre», «La iniciación», «La primera tarea», «El primer escalón», «El segundo escalón», «El descubrimiento», «Tercer escalón», «El trono», «La caída». Con estos nombres se identifican algunos elementos típicos del camino heroico, que no es necesario ejemplificar ahora. Solo se señalará que los capítulos que indican «escalón» narran cómo el personaje asciende en la jerarquía social, con astucias que incluyen el asesinato, hasta construirse un trono y ocupar el rango principal. Por su parte, el capítulo llamado «El descubrimiento» narra el desplazamiento del héroe hacia tierras lejanas, de donde vuelve, en este caso, con un conocimiento técnico y alimento. Este proviene de que encuentra un depósito con latas de comida, y el otro, de que allí vive «la Guerrera», quien le enseña a Plop y a un grupo de elegidos técnicas de combate.

Más allá de las semejanzas y diferencias con el monomito, lo singular de Plop, como en el arquetipo, es la búsqueda del autoconocimiento. Esto es lo que lo saca de la zoología en la que viven sus compañeros. Y al conocerse, por sinécdoque, reconoce a la sociedad de la cual forma parte. En este sentido, es él quien permite realizar la lectura del texto en torno a lo que permanece y desaparece después de una debacle, porque mediante sus desplazamientos, el lector descubre dónde y cómo vive el héroe.

Primero, entonces, el nacimiento, luego el bautismo, después la iniciación (un ritual de la tribu de Plop que marca el pasaje de la infancia a la adultez); más tarde, el viaje hacia tierras lejanas y el descubrimiento del depósito, que, por hallarse en un subsuelo, representa una katábasis o el período en el vientre de la ballena; el posterior regreso y la asunción del poder. Sin embargo, no se convierte en patriarca $^{13}$, por el contrario, se transforma en déspota $^{14}$. De esta manera, Plop cae

\footnotetext{
${ }^{13}$ Es curioso que, en las otras novelas de Rafael Pinedo, las protagonistas sean heroínas (Frío y Subte). Los dos personajes son excepcionales, porque se autoabastecen al margen del grupo, y cuestionan el «patriarcado», además de tener impulsos homosexuales.
} 
por su propio peso. En su caso, además, no solo se trata de la misma corrupción por el poder que sufrieron los dirigentes anteriores a él; porque él, a diferencia de aquellos, padece una hybris más significativa: ambiciona el poder, lo consigue, y una vez satisfecho su deseo, desmerece el conocimiento que lo llevó hasta allí (la cultura textual que le transmitió la vieja Goro).

Ahora, para ilustrar más la lectura, vale preguntarse si Plop es un texto netamente «pesimista». Habría que considerar que la novela cuenta con dos elementos paratextuales especiales: uno de ellos es el epígrafe, con versos de «Comida», una canción de Titãs, una de las bandas de rock brasileñas de mayor éxito durante los años ochenta:

\section{Bebida é água \\ comida é pasto \\ Você tem sede de qué? \\ Você tem fome de qué? (Titãs 1982: track 2).}

Para la historia de Plop, donde se tematiza el tópico literario argentino del hambre, ¿qué sentido puede tener este fragmento? La canción continúa así:
A gente não quer só comida
A gente quer comida, diversão e arte
A gente não quer só comida
A gente quer saída para qualquer parte (Titãs 1982: track 2).

Es decir, se necesita comida para supervivir, pero se necesita algo más que ella para trascender la mera existencia. De este modo, Rafael Pinedo señala ese deseo inalienable de ir más allá, ¿pero qué representa argumentativamente?

El otro elemento paratextual es la dedicatoria: «A Sofía y Max, para cuando puedan leerlo». En otras palabras, consta que estos niños, cuando tengan la edad suficiente, leerán la historia de Plop, acaso para aprender algo de ella.

Y también cabe pensar en el acto de hacer una obra de arte. Aunque esta vehiculice la crítica social más desesperanzada y se muestre, en la ficción, el panorama más desalentador («la destrucción de la cultura», en este caso), persiste la confianza en la comunicación humana, implicada en el vínculo que se entabla con el receptor del mensaje.

¿Qué queda, en resumen, después del «fin»? La lista es extensa. Perduran los deseos primarios, la ambición, el comercio, la necesidad de agruparse, la especulación; sentimientos como la envidia, la vanidad, la soberbia, la insatisfacción, la venganza, el rencor; la dimensión del fingimiento y la mentira; también el amor como fuerza misteriosa e inevitable, la amistad, la risa, la seducción. Perduran, significativamente, las nociones de jerarquía y de centro, y los conceptos asociados, como movilidad y diferencia y prestigio sociales, como así también las metáforas de lo «alto» y lo «bajo»; la esfera del honor, la

\footnotetext{
${ }^{14}$ Cfr. el proceso de maduración cultural que trabajó Lévi-Strauss, con sus tres instancias: lo crudo, lo cocido, lo podrido.
} 
extranjería, el castigo, los líderes, los abusos. Perduran la idea de origen y la dimensión política de los nombres, la necesidad de una religión como evasión y la construcción de tabúes, entre muchas cosas más. Y perdura, sobre todo, la conciencia mitológica.

En definitiva, permanecen los mecanismos semióticos, es decir, la facultad de crear significado y representar. El material aparentemente nuevo de la significación en la cultura de Plop tiene claras raíces en la cultura del autor. Este, como persona de carne y hueso, para hablar de un futuro hipotético en la realidad de la ficción, se remite al pasado/presente de la «realidad real». Y como se sabe, la ciencia ficción hace un pronóstico que se basa en estructuras preexistentes.

Viene al caso, pues, un fragmento escrito por Herman Hesse:

Si el género humano se extinguiera con la sola excepción de un niño medianamente inteligente, sin ninguna educación, este niño volvería a descubrir el curso de todas las cosas y sabría producir de nuevo dioses, demonios, paraísos, prohibiciones, mandamientos y Viejos y Nuevos Testamentos (1993: 131).

Esto es, exactamente, lo que sucede con Plop. Entonces, luego del «fin», permanece un manojo de pulsiones vitales y la capacidad de crear estructuras semióticas, acaso una cualidad inherente del hombre, junto con su animalidad.

«... aunque la pampa se trague al planeta» (Benesdra 2012: 29), la cultura continuará; y si desapareciera, nadie viviría para contarlo. Esto lleva a pensar que la saga del posapocalipsis de Rafael Pinedo, con independencia de su propuesta de lectura (la desaparición), gira en torno a un cuestionamiento crítico del estado vigente de la cultura y una proyección imaginativa sobre el empeoramiento de todo lo que podría empeorar.

Al respecto, se cita un fragmento de James Berger (retomado por Alejo Steimberg para hablar sobre una tendencia de la literatura argentina posterior al 2001 hacia un cronotopo (pos)apocalíptico):

The apocalypse $[\ldots]$ is The End, or resembles the end, or explains the end. But nearly every apocalyptic text presents the same paradox. The end is never the end $[\ldots]$. In nearly every apocalyptic presentation, something remains after the end. [...]. In modern science fiction accounts, a world as urban dystopia or desert wasteland survives [...]. The study of post-apocalypse is a study of what disappears and what remains. (Berger 1999: 5-7) ${ }^{15}$

No es accesorio decir que el género literario apocalíptico es en sí mismo mitologizante e, incluso como mito, data de tiempos anteriores a la elaboración del Apocalipsis bíblico, escrito aproximadamente en el siglo I o II después de Cristo,

\footnotetext{
15 "El apocalipsis [...] es El Fin, o se asemeja al fin, o explica el fin. Sin embargo, casi todos los textos apocalípticos presentan la misma paradoja. El fin nunca es el fin [...]. En casi todas las presentaciones apocalípticas, algo permanece después del final. [...]. En los relatos de ciencia ficción moderna, sobrevive un mundo urbano como distopía o páramo desierto [...]. El estudio del posapocalipsis es un estudio de lo que desaparece y de lo que permanece." (trad. propia).
} 
cuando las persecuciones romanas a los cristianos eran cruentas. También existen fuentes apocalípticas en la cultura helena antigua y referencias al fin del mundo en el Libro de Daniel, del Antiguo Testamento.

De esta forma, cabría interpretar Plop sin anclajes sociohistóricos definidos, como variación fantasiosa sobre el tema del malestar de la cultura mundial. Sin embargo, mediante el rastreamiento de formas verbales, tópicos literarios y algunas referencias culturales más, el texto enraíza en la Argentina de los últimos años. Así funcionan, dentro del programa posapocalíptico, las alusiones al desierto pampeano argentino o al tópico del hambre.

Además, como ya se ha dicho, y contra lo que se podría esperar, la imaginación apocalíptica o cienciaficcional tiene un punto de partida y contraste permanente irrefutable en el presente histórico del autor del que se trate. Para Plop, el contexto de producción está conformado, entre otras referencias de índole diversa, por la crisis social que generó la adopción del capitalismo, sin regulación estatal, en 1976, acentuado durante la llamada década menemista, con la consecuencia lógica y traumatizante del estallido económico y social del 2001, que afectó, en diferentes grados, a toda la sociedad argentina.

Este país había permanecido más o menos acrítico con respecto al discurso «posmoderno» que proponía el fin de fines (Fukuyama, por ejemplo, con el fin de la Historia). Aunque ciertos ministros de Economía pronosticaran un crecimiento nacional ininterrumpido, este no era un «país del primer mundo», y desmentía con su misma existencia las promesas democratizantes del acceso a la información de la «aldea global» y demás falacias de la globalización, según las cuales se favorecería a todo el mundo, y no solo al imperialismo. Sin embargo, ante la crisis del 2001, los centros académicos, donde siempre habían sobrevolado estas ideas, tuvieron que aceptar la evidencia: se estaba mal y se iba peor. El cambio de siglo, ahora sí, parecía ir acompañado por un cambio de época: ¿qué es lo que estaba cambiando?, ¿qué permanecería?, ¿qué desaparecería?

La crisis económica estuvo acompañada de una crisis representacional. Como dijo Lotman (también influido por su contexto histórico), si cambian las condiciones de producción, inevitablemente cambia la cultura, y con ella sus productos. Esto podría valer para comprender mejor la distopía que se evidencia en una parte significativa de la narrativa argentina contemporánea, donde son frecuentes los paisajes apocalípticos o posapocalíticos.

En estas latitudes, sin embargo, nunca arraigó profundamente la ciencia ficción. Pablo Capanna, como la mayoría de los estudiosos, baraja el argumento de la falta de desarrollo tecnológico, que sí han tenido los países primermundistas, donde fue más habitual la producción y circulación del género, en su sentido más frecuente. «Lejos de los habituales temas de la tecnología moderna, Plop es ciencia rudimentaria y ficción de ruinas», dice la misma contratapa de la novela analizada.

Para una investigación futura, resta comprobar lo que ha sido demostrado con el caso de Plop en otros textos contemporáneos: la fertilidad del camino del héroe, fusionado con elementos de la ciencia ficción especulativa, para problematizar críticamente la realidad, es decir, la apelación a las estructuras arquetípicas de la cultura, como datos elementales, con el acento temporal o atributo señalado por medio de la ciencia ficción. ¿Se trataría de una posición intermedia entre el esencialismo y el materialismo? 
Sea como fuera, Pinedo tiene el mérito de haber ilustrado el mecanismo semiótico. Muy lejos de aquello que aparentemente buscó (imaginar la destrucción), reafirmó la imposibilidad de destruir la cultura: siempre permanecerá la capacidad de crear significado, aunque cambien los códigos.

Sin embargo, la memoria colectiva podría perder textos $\mathrm{y}$, entre ellos, la definición de humano como ser capaz de sublimar la violencia por medio del lenguaje. Y esto no debería pasar inadvertido, aunque la cultura nunca cumpla su promesa de darlo todo.

Además, Pinedo pone una señal de alerta aquí, cuando muestra personajes que apenas se diferencian del animal y, no obstante, no se sorprenden de esto. Por el contrario, naturalizan las condiciones impuestas, sin cuestionarlas, y se preocupan nada más que por supervivir, para granjearse el beneficio de morir.

Finalmente, ahora sobre el final de esta investigación, recuérdese que Lotman se preguntó porqué el hombre ha empleado siempre grandes reservas de energía para producir pensamiento teorético, conocimiento en todas sus formas y expresiones artísticas de la más variada índole. Y respondió que la cultura no es un complemento facultativo para la humanidad, sino la condición necesaria, sin la cual, su misma existencia aparece como imposible.

El hombre no es ni Dios ni máquina. Y si se olvidara de ser precisamente hombre, acaso la maleza crecería en las ruinas de la Historia y de sus ojos.

\section{Referencias bibliográficas}

Alonso, A, "Entrevista con el escritor Rafael Pinedo", Axxón 10 de marzo, 2004. Disponible en: http://axxon.com.ar/not/136/c-1360035.htm

Berger, J. After the End. Minneapolis: University of Minnesota Press, 1999.

Borges, Jorge Luis y María Esther Vázquez. Literaturas germánicas medievales. Buenos Aires: Falbo Librero Editor, 1965.

Benesdra, S. El traductor. Buenos Aires: Eterna Cadencia, 2012.

Campbell, J. El héroe de las mil caras. Buenos Aires: FCE, 2010.

Capanna, P. Ciencia ficción, utopía y mercado. Buenos Aires: Cántaro, 2007.

Costa, F., "Ciencia ficción en la Argentina. La máquina de inventar sueños", Revista Ñ, 20, agosto 2000, pp. 6-7.

Dellepiane, Á.B., "Narrativa argentina de ciencia-ficción. Tentativas liminares y desarrollo posterio", en Actas del IX Congreso de la Asociación Internacional de Hispanistas. Francfort: [s. d.], 1989, pp. 75-87.

Di Paolo, O. "El poshumanismo apocalíptico en la novela negra argentina contemporánea: Ciudad santa y 77", Literatura y lingüística (SCIELO) 25, 2012, pp. 39-59.

- Gemidos y explosiones apocalípticas poshumanas. La novela negra y de ciencia ficción hispana del siglo XXI. Madrid: Editorial Pliegos, 2013.

Drucaroff, E. Los prisioneros de la torre. Política, relatos y jóvenes en la postdictadura. Buenos Aires: Emecé, 2010.

García Gual, C., "Mitología y literatura en el mundo griego", Amaltea. Revista de Mitocrítica 0, 2008.

Eliade, M. Imágenes y símbolos. Madrid: Taurus, 1974.

- Mito y realidad. Barcelona: Kairós, 2006.

Friera, S. “Argentina ayuda mucho al pesimismo, Página 12, 17 de enero, 2006. Disponible en: http://www.pagina12.com.ar/diario/suplementos/espectaculos/4-1552-2006-0117.html 
Hesse, H. Demian. Madrid: Alianza, 1993.

Jung, C.G. Obra Completa. Vol. 9: Los arquetipos y lo inconsciente colectivo. Madrid: Editorial Trotta, 2002.

Kohan, M., "El fin de una épica”, Punto de vista. Revista de cultura 64, agosto, 1999.

López Casanova, M. Literatura argentina y pasado reciente. Relatos de una carencia. Buenos Aires: Universidad Nacional de General Sarmiento, 2008.

Lojo, M.R., “Cómo se hacen los héroes?”, Revista Ñ, 2 de febrero, 2010. Disponible en: http://edant.revistaenie.clarin.com/notas/2010/02/20/_-02143713.htm

Lotman, I. Semiosfera I. Madrid: Cátedra, 1996.

- Semiosfera III. Madrid: Cátedra, 2000.

— "Sobreviviremos si somos sabios", Entretextos. Revista Electrónica Semestral de Estudios Semióticos de la Cultura 10, noviembre, 2007. Disponible en: https://dialnet.unirioja.es/servlet/articulo?codigo=2480565\&orden=141785\&info=link

Lotman, I. y Z.G. Mints. Literatura y mitología. Semiosfera I. Madrid: Cátedra, 1996, pp. 129-142.

Malinowski, B. La vida sexual de los salvajes. Madrid: Morata, 1975.

Molina Ahumada, E.P., "Constelación mítica y cielo de la saga. Acerca de la relación mito/saga contemporánea", en M. I. Arriazabalaga, A. Leunda y P. Molina (comps.). Bajo el cielo de la saga. Hacia una neoépica argentina. Córdoba: Facultad de Lenguas, UNC, 2011, pp. 29-53.

Pampa Arán, O., "Juri Lotman: actualidad de un pensamiento sobre la cultura", Escritos, Revista del Centro de Ciencias del Lenguaje 24, jul.-dic., 2001, pp. 47-70.

Pinedo, R. Plop. Buenos Aires: Interzona, 2012.

Reati, F. Postales del porvenir. La literatura de anticipación en la Argentina neoliberal (1985-1999). Buenos Aires: Biblos, 2006.

Ricoeur, P. La memoria, la historia, el olvido. Buenos Aires: FCE, 2013.

Sábato, E. La cultura en la encrucijada nacional. Buenos Aires: Sudamericana, 1982.

Steimberg, A., "El futuro obturado: el cronotopo aislado en la ciencia ficción argentina pos2001”, Revista Hélice 14, enero, 2012, pp. 4-19.

Titãs, "Comida", en Jesus não tem dentes no país dos banguelas [CD]. Río de Janeiro: WEA, 1982.

Zylko, B. (2005, may. 5). "La cultura y la semiótica. Notas sobre la concepción de cultura de Lotman", Entretextos. Revista Electrónica Semestral de Estudios Semióticos de la Cultura 5, mayo, 2005. Disponible en: https://www.researchgate.net/publication/28088245_Cultura_y_Semiotica_Notas_sobre _la_concepcion_de_cultura_de_Lotman 